\title{
COACHING IN BALTIC STATES (LITHUANIA, LATVIA AND ESTONIA): A EUROPEAN SURVEY
}

\author{
${ }^{1}$ Jonathan Passmore, ${ }^{2}$ Aiste Dromantaite, ${ }^{3}$ Hazel Brown \\ ${ }^{1}$ Professor, Henley Business School, University of Reading, United Kingdom \\ Email address j.passmore@henley.ac.uk \\ ${ }^{2}$ Assoc. prof. dr. Mykolas Romeris University, Vilnius University, Lithuania \\ Email address aiste.dromantaite@gmail.com \\ ${ }^{3}$ Dr. University of Winchester, United Kingdom \\ Email address hazel.brown@winchester.ac.uk
}

Received 1008 2019; accepted 20122019

This paper presents the results from a study exploring coaching practices in European. The survey covered 50 European countries, was undertaken in 31 languages with approaching 2500 participants engaged in the coaching industry and involved a partnership of over 100 professional bodies, universities and networks, who helped to promote the online survey.

This paper focuses on the results from the Baltic States including Lithuania, Latvia and Estonia, where there has been little research into coaching practice despite the growth of coaching. It builds on other national published studies drawing on the same research.

The results from this study show that coaching in Lithuania is broadly similar to wider European practice. Interesting differences include the limited use of supervision, the relatively low fee rates when compared with European averages and the importance placed on continuous professional development by Baltic coaches. In general, the data suggests that while coaching is growing, in scale and scope, it remains comparatively immature compared with some other European States when coaching has a twenty to thirty-year history of progress and development.

Keywords: coaching, coach, coaching research, management, preferences.

JEL Classification: M5.

\section{Introduction}

Coaching's development is often traced back to the mid-1980s when it emerged in the North America as a tool for organisational and personal development, although as Passmore and Lai (2019) note the use of coaching goes back to at least the early part of the twentieth century with its popularity as a tool in education settings, for example with debating societies (Trueblood, 1911; Huston, 1924). Other including Brock (2012), Cluterbuck, Megginson (2005), Whitmore (2002) have noted its origins in therapy, mentoring and sports. Coaching is best understood as a tool to help others to explore and solve their questions.

Copyright (C) 2019 The Authors. Published by Vytautas Magnus University. This is an open-access article distributed under the terms of the Creative Commons Attribution-NonCommercial 4.0 (CC BY-NC 4.0) license, which permits unrestricted use, distribution, and reproduction in any medium, provided the original author and source are credited. The material cannot be used for commercial purposes. 
While a wide range of definitions still exist, we have adopted the following definition: "a Socratic based future focused dialogue between a facilitator (coach) and a participant (coacheel client), where the facilitator uses open questions, summarises and reflections which are aimed at stimulating the self-awareness and personal responsibility of the participant" (Passmore, Fillery-Travis, 2011).

Coaching can be used to help managers and employees address issues of work performance and potential and its use has expanded significantly. Over the past thirty years coaching research has also developed and good evidence now exists for its effectiveness as an intervention, to address sub-clinical issues (Theeboom Beersma, Van Vianen, 2013; Jones, Woods, Guillaume, 2015; Grover, Furnham, 2016). Coaching is now considered one of the most effective ways to improve and enhance the skills and abilities of employees, as well as support employee well-being and retention.

The developing nature of work is increasing these demands in the $21^{\text {st }}$ century. Schon and colleagues noted (Schor, Bachkirova, Smith, 2015) higher levels of consumption are driving longer working hours, and higher level of workplace stress. While not a silver bullet the implementation of a coaching culture in organization can help employees ease these challenges by improving goal setting behaviours, addressing unhelpful thinking patterns and enhancing self-awareness and selfcompassion. As a result, coaching activity has been growing, both through the number of coaches but also wider application of coaching to new areas of practice from safety coaching to driver development, and from offender management to the armed services.

In Lithuania, little research has been undertaken into the application of coaching (Dromantaite, 2014). Further cross-cultural comparison of coaching practice in Lithuania and other countries in Europe has to-date not been undertaken, exploring other Baltic coach practice compares with practices in the UK or wider European Union (see Passmore, Brown, Csigas, 2017; Passmore, Brown, Peebles, Grajfoner, 2018; Passmore, Brown, Tee, 2018; Tee, Passmore, Brown, 2019).

Despite this limited amount of published research in the Baltic States coaching has matured considerably with more companies interested in the potential of coaching as a tool to help their employees alongside the growth of personal coaching.

There has been a major expansion of coaching in the area of executive education and development. Coaching has become a standard feature in areas such as:

- Modular leadership development programmes;

- Graduate development programmes, coupled with mentoring;

- Middle management development.

The use of internal coaches is also featuring more, with larger organizations developing their own internal coaching pools and supplementing these with external coaches where necessary. 
Alongside these developments, the number of professional coaches is also growing. The main professional body in the region, International Coach Federation (ICF) reports the following levels of membership as at January 2020:

- Latvia - 26 members, 14 qualified (credentialled) coaches;

- Lithuania - 22 members, 17 qualified (credentialled) coaches;

- Estonia - 33 members, 15 qualified (credentialled) coaches.

This paper aims to explore developing coaching practice in Lithuania and the other Baltic States, and to compare the received data with European Union countries.

\section{Methodology}

2.1 Sample

This study was drawn from an international sample of 2267 coaches $^{1}$. The international sample was drawn from more than 47 European countries spanning from Iceland in the west to Russia in the east and from as far north as Norway down to Turkey in the south. Initially 50 countries were included, but no responses were received from a small number of countries including Greenland, Belarus and Moldovia. The international sample consisted of 1441 female (64\%) and 819 male (36\%) coaches (seven missing), who were principally between 30 and 64 years old (53 coaches were 18-29 years old: 1080 coaches were in the 30-49 year-old age bracket; 1016 coaches were aged 50-64; while only 107 coaches were over 65).

In the three Baltic States the questionnaire was shared with the ICF coaching community and through social media to reach coaches outside of the professional coaching body community. In total 62 responses were received from three Baltic countries: 14 from Estonia, 20 from Latvia and 28 from Lithuania. This data was combined for the purpose of this article and used in comparison with responses from the wider European sample.

\subsection{Procedure}

The survey was developed through international collaboration, involving 50 research groups, each from a different country. Each national research group decided whether the survey should be translated and if so into what language or languages. In total the survey was translated into 31 local languages. The decision to undertake a translation was made by each local research team, who led the process. The items were translated by one team member with a second team member, undertaking a parallel translation, and discussion and agreement on the final draft. In each country a snow balling method of recruitment was used as the aim was to recruit beyond the traditional professional boundaries, reflecting the unregulated ad diverse nature of coaching practice.

Each national research team was responsible for sharing the survey with their coaching community and, thus, the process involved connections with national and

\footnotetext{
${ }^{1}$ From 2267 coaches, we excluded 685 participants, who did either not describe themselves as coaches).
} 
professional bodies. In total, over 100 professional and coaching-related bodies shared the research link with their members. The survey was designed to take approximately 25 minutes to complete.

\subsection{Questionnaire Measures}

Participants were asked about their age, former experience, education, and their coaching practice. Besides questions about demographic data, the coaches were also asked about their coaching experience, coach training and details about their coaching practice, including their fee rates for individual and organisational coaching (per hour), how they rated themselves compared to colleagues and the extent they used supervision, self-reflection, and forms of personal development. Most of these measures were ordinal scaled, as we expected that coaches have difficulties in estimating the exact number of hours in coach training, coaching experience, and self-reflective practice; thus, we wanted to provide categories that they can help them estimate their amount.

Coach training. The coaches were asked about their coach training with the question "What is your highest coaching qualification". The coaches had to answer on an ordinal scale ranging from 1 to 10 , where 1 was "less than 2 hours of training", 2 was "2-6 hours of training", 3 was "7-16 hours of training", learned 4 was "17-49 hours of training", 5 was "50-99 hours of training", 6 was "100-199 hours of training", 7 was " $200-400$ hours of training", 8 was " 400 or more hours of training", 9 was "under-graduate coaching degree (3 years full-time)", and 10 was "postgraduate coaching degree (1 year full time/2 years part-time)".

Coaching experience. The coaches were asked about their years of experience with the question "How many years have you practiced as a coach". The coaches had to answer on an ordinal scale ranging from 1 to 7 , where 1 was "less than 12 months", 2 was " $1-3$ years", 3 was " $4-7$ years", 4 was " $8-12$ years", 5 was " $13-15$ years", 6 was " $16-20$ years", and 7 was "more than 20 years".

Coaching quality. The coaches were asked to rate their coaching quality with the following question "How would you rate the quality of your coaching when compared with other coaches" on a Likert scale ranging from 1 (low) to 10 (best).

Self-reflective practice to ensure coaching quality. For quality-control processes, we used three different measures: the coach's use of self-reflection (How much time do you spend per week on reflective practice?), the coach's use of supervision (How often do you receive formal coaching supervision?), and the coach's use of self-evaluation (How do you evaluate the impact of your coaching?). The self-reflection scale was ordinal-scaled, ranging from 1 (<60 min.), 2 (60-90 min.), 3 (90-120 min.), 4 (120-240 min.) to 5 (> $240 \mathrm{~min}$.). The supervision scale was also ordinal and ranged from 1 (I do not receive supervision), 2 (1 hour of supervision for more than 100 hours of coaching with clients), 3 (for every 51-100 hours), 4 (for every 26-50 hours) to 5 ( 1 hour of supervision for every 25 hours or less of coaching with clients). Regarding self-evaluation, coaches were asked to 
provide details of the means and frequency of self-evaluation feedback they received (When asked by the client; periodically on a random sample of client; formally at the end of every coaching session; informally at the end of every coaching session; formally at the end of every coaching process; informally at the end of every coaching process; I have not formally evaluated my work in the past twelve months; other). This data was formed into an ordinal scale, ranging from 0 (no selfevaluation), 1 (self-evaluation at times), 2 (self-evaluation after every coaching process) to 3 (after every session).

\subsection{Statistical Analysis}

IBM SPSS Statistics 24.0 (IBM Corporations, Chicago, 2016) was used for the computations described in the results section.

\section{Results}

\subsection{Biographical information education and employment}

Comparing data by gender, it showed that there were $68 \%$ of women and $32 \%$ men who participated in this research from Baltic States. The exact percent of Lithuanian participants were $64 \%$ of women and $36 \%$ men. These figures compare with the number of European sample where $60 \%$ of female and $40 \%$ men. In the UK the response was $63 \%$ of women and $35 \%$ men (see Figure No. 1).

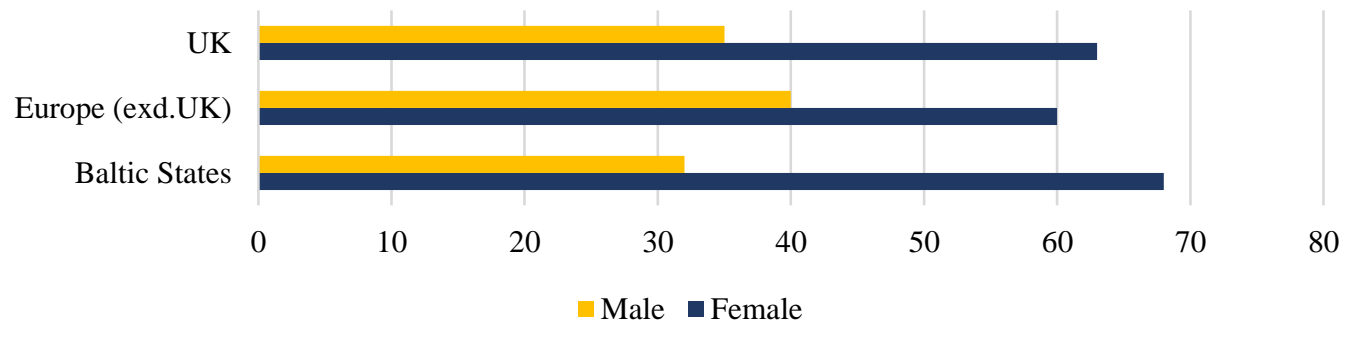

Figure 1. Gender of participants, \%

These figures confirm is relatively feminine as a profession. Several possible factors may explain the larger female representation in coaching than the wider workforce. The first is that employment is part time and flexible, meaning woman can inter weave coaching with their other responsibilities.

A second factor is that coaching may be viewed as an extension of the caring professions, such as teaching, nursing and counselling, where higher rates of female employment are also seen. When coaches' age was analysed, the data shows that most coaches who responded were $30-49$ years old in both Lithuania and Europe countries, i.e. $85.7 \%$ in Lithuania, this compares with $48.8 \%$ in Europe. The next largest age group in Europe was aged 50-64, 43,4\% in Europe. However, in Lithuania only $7,1 \%$ were in this age group (see Figure No. 2). 


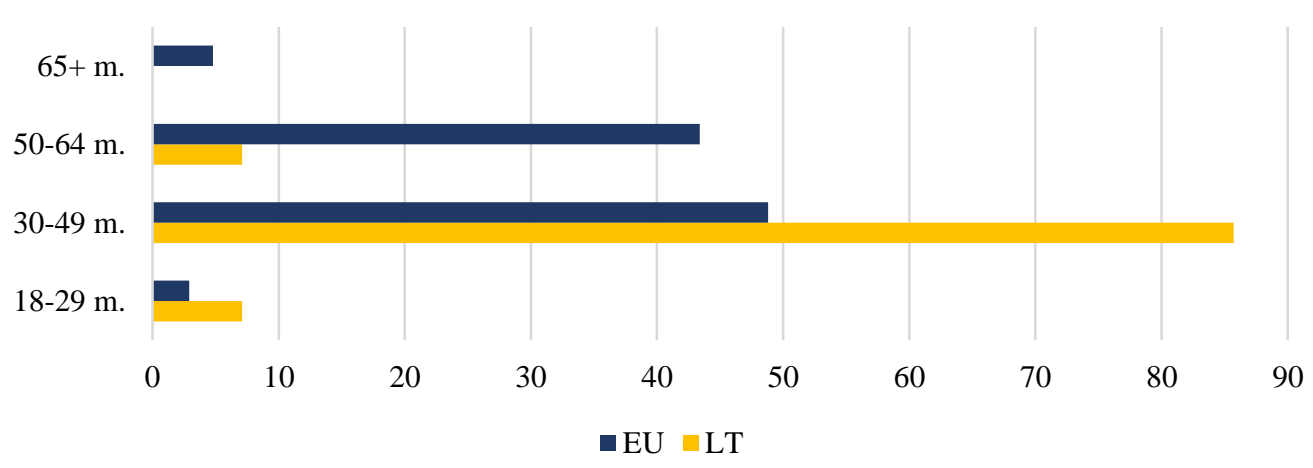

Figure 2. Age of coaches in Lithuania and EU, \%

The age difference may reflect coaching has emerged relatively recently in the Baltic States compared with the wider EU and UK, meaning the coaching population has not had an opportunity to 'age' in their professional roles. This hypothesis appears to be supported by the data in Figure 3 which confirms that, coaches in Lithuania have fewer years of coaching experience than across Europe.

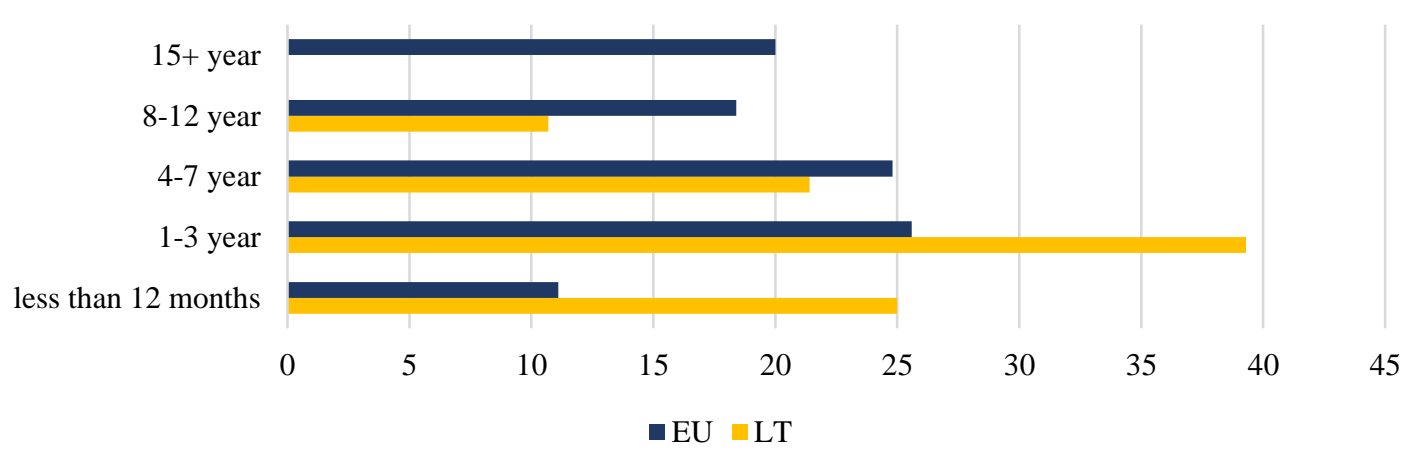

Figure 3. Coach experience by years in Lithuania and EU, \%

If we analyse coaches' highest non-coaching education, the collected data showed that more than $60 \%$ of coaches have acquired master degree, $32 \%$ have a bachelor degree, around 4\% have a vocational education and 4\% PhD's. We can conclude in Lithuania are highly educated when compared to the wider population.

In terms of coaching education, $64.2 \%$ of Lithuanian coaches them have from 50 to 400 hours' training, $14.3 \%$ of coaches - more than 400 hours and only $10.8 \%$ reported having 2- 49 hours of coach education. (see Figure No.4). These figures reflect the relatively high hours required by the ICF for Professional Coach (PCC) accreditation when compared with other craft-based professions, such as Pilates or bricklaying, but low when compared to high status professions such as accounting or law. 
coaching master degree studies (full-time/part-time studies) coaching bachelor degree (full-time studies) more than $400 \mathrm{~h}$ trainings and studies 200-400 $\mathrm{h}$ trainings and studies 100-199h trainings and studies 50-99 $\mathrm{h}$ trainings and studies 17-49 h trainings $7-16 \mathrm{~h}$ trainings 2-6 h trainings less than $2 \mathrm{~h}$ training

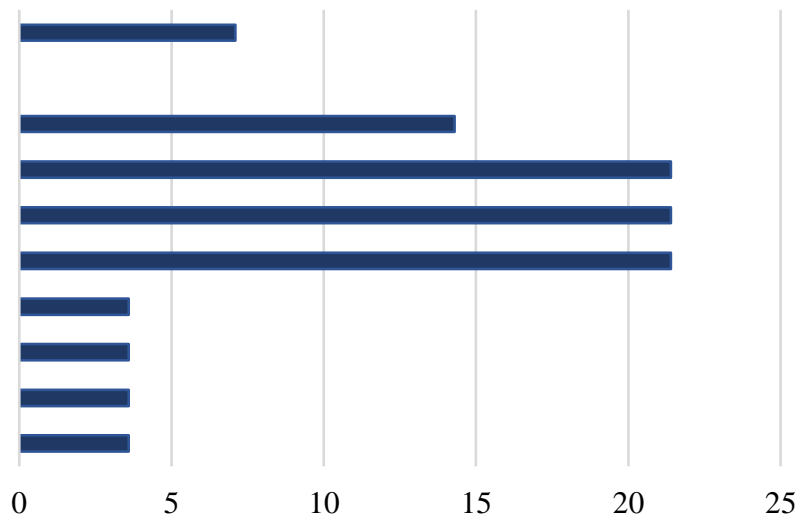

Figure 4. Acquired qualification in coaching, $\%$

Most participants worked in small scale private organizations or had own coaching business. 667\% reported they were coaching specialists, $14.8 \%$ were from international private organizations, $11.1 \%$ from governmental and public organizations, and 7.4\% - from non-profit organizations and other NGOs. Most were organizations established within the last 5 years $-44.4 \%$, with $14.8 \%$ within 5-10. In comparative terms the data showed that coaching in Lithuania is more likely to be situated within single person organisations compared with Europe, where large providers have coaching have become more common. This may reflect the stage of development of the Baltic market, where coaching is less well established than in some other European countries such as the UK, and as coaching developers' larger provider may emerge and capture more of the coaching market. Figure 5 reports the results from individual categories of job roles.

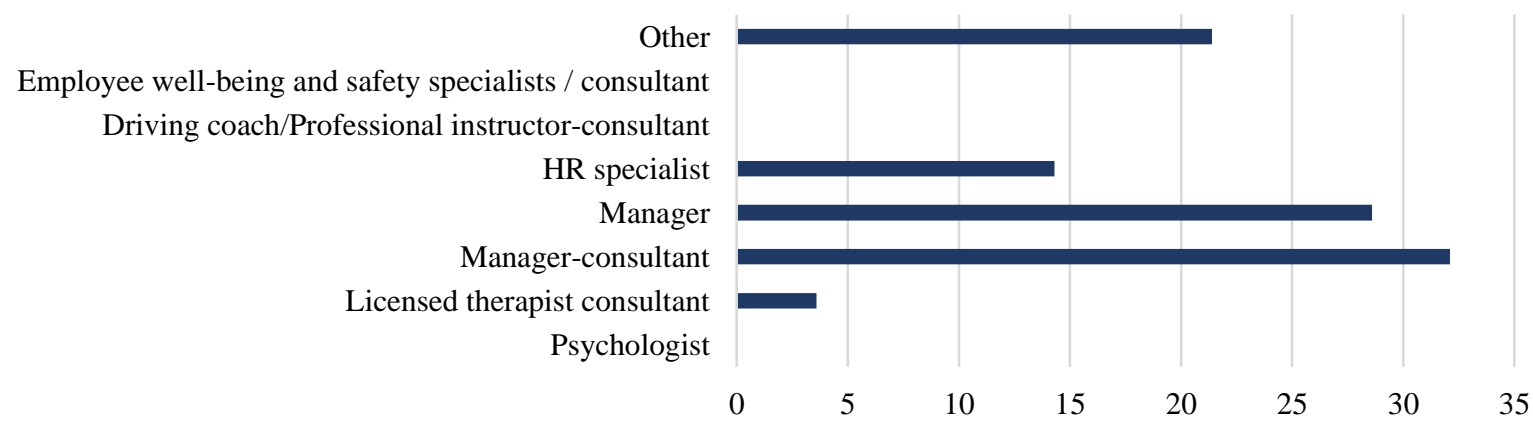

Figure 5. Coach position in Lithuania, \%

\subsection{Contracting}

Contracting is an important element within the coaching relationship. It sets the ground rules between the coach and the individual client, but also provides the framework between the coach (provider of the coaching service) and the organisational sponsor. We were interested to explore how coaches in different countries may be using contracting. 
Most contracts were verbal agreements between the coach with individual clients (coachee). The second most popular approach was a written contract with the organization and verbally with other parties. This marked $21 \%$ of Baltic States' coaches, $22 \%$ by Europe and $18 \%$ by UK.

\subsection{Primary client}

We also explore attitudes to who the coach believed was their primary client "Who do you believe is the primary client when you "are delivering corporate/organizational coaching?". An answer "Individual client" was marked mostly and this done $62 \%$ UK coaches, 55\% Europe and 43\% Baltic States' coaches. The contrast between the Baltic States and the UK was interesting to note with Baltic coaches placing greater attention to organizational needs in comparison to the UK (Figure 6).

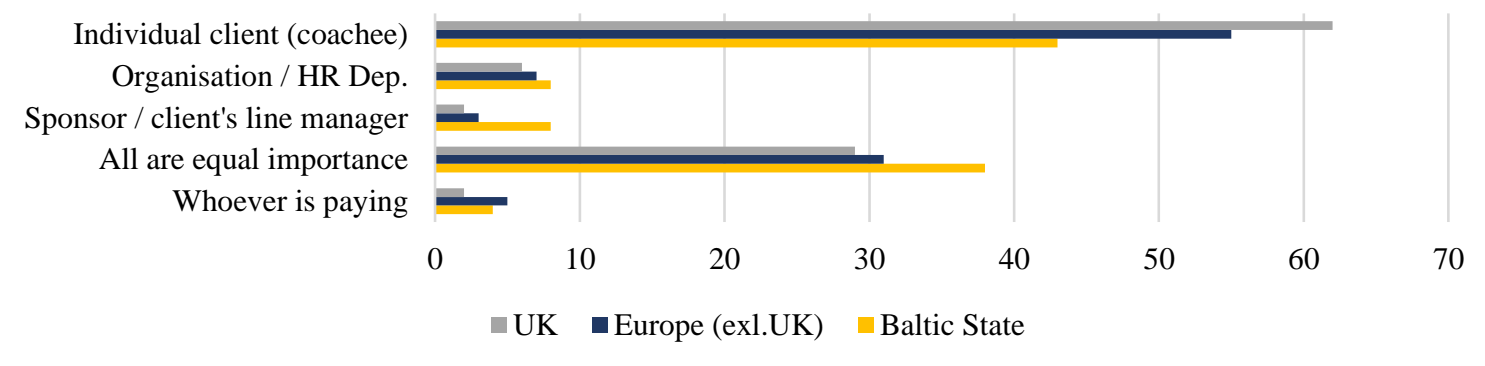

Figure 6 . The primary partners, $\%$

\subsection{Fees: Corporate and Personal fee rates}

In reviewing corporate coaching fees rates across Europe, we found rates reflected wider economy rates of pay, with higher rates in the Western and Northern European countries and on average lower rates in Southern and Eastern European countries included in the survey. In the Baltic States the results shows $101-199$ Euros was the most popular rate, with few coaches charging above 200 Euros and none above 400 Euros per hour (see Figure No. 7).

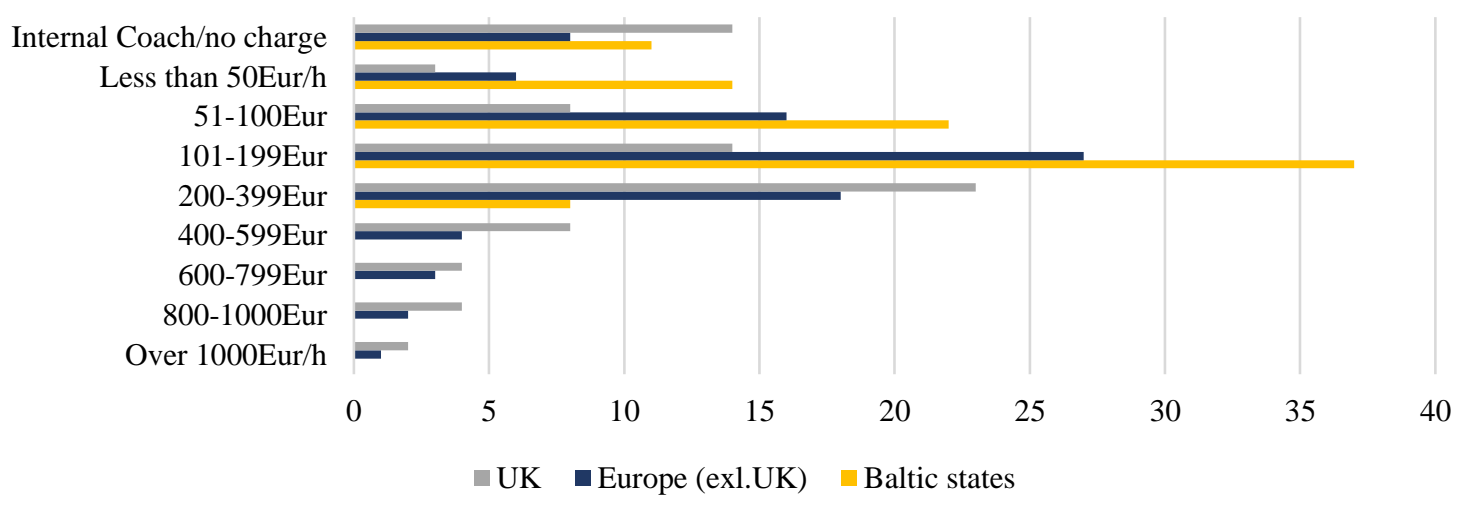

Figure No. 7. Hourly fee rates: corporate funded coaching, $\%$ 
Unsurprisingly rates for individual clients were lower across Europe and in the Baltic for individual clients, where fees were typically below 50 Euros per hour (see Figure No. 8).

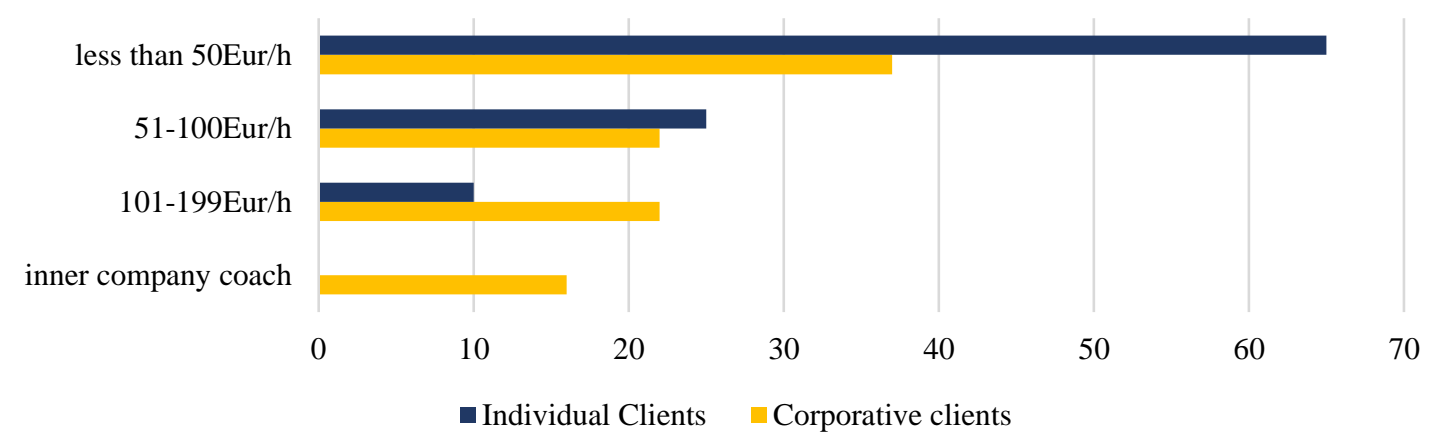

Figure 8. Hourly fees per corporative and individual clients, $\%$

This survey data can be compared with other market information (Sherpa Coaching, 2019) which suggested that executive coaches received an average of 355Euro per hour. In 2018, it was 344Eur and 314USD in 2017. The data for 'business coaches' was 224Euro per hour, down from last year's average of 249Euros. The closest figure to the data from this sample was for life coaches, which equates to personal coaching, where rates claimed were 185Euro, an increase over last year at 170Eur per hour. In comparing this survey with the results from Sherpa we can assume the Sherpa data was Western European biased, reflecting the lack of translation of the Sherpa survey and its smaller and more restricted sample.

\subsection{Evaluation}

In terms of evaluation the data shows that most of Baltic States coaches do this informally with a preference for a review at the end of every meeting, with 55\% of respondents selecting this option (see Figure No. 9).

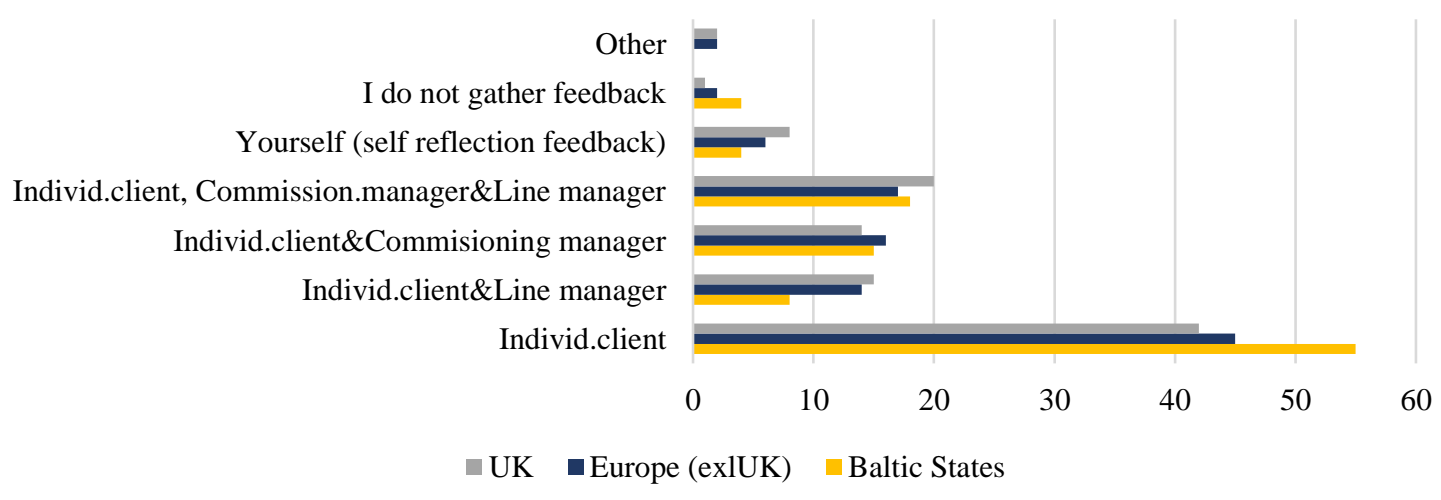

Figure 9. Gathering feedback, $\%$ 
In terms of coaching focus, most coaches in the survey appeared to focus on workplace issues, with a smaller group focusing on personal issues (see Figure No. $10)$.

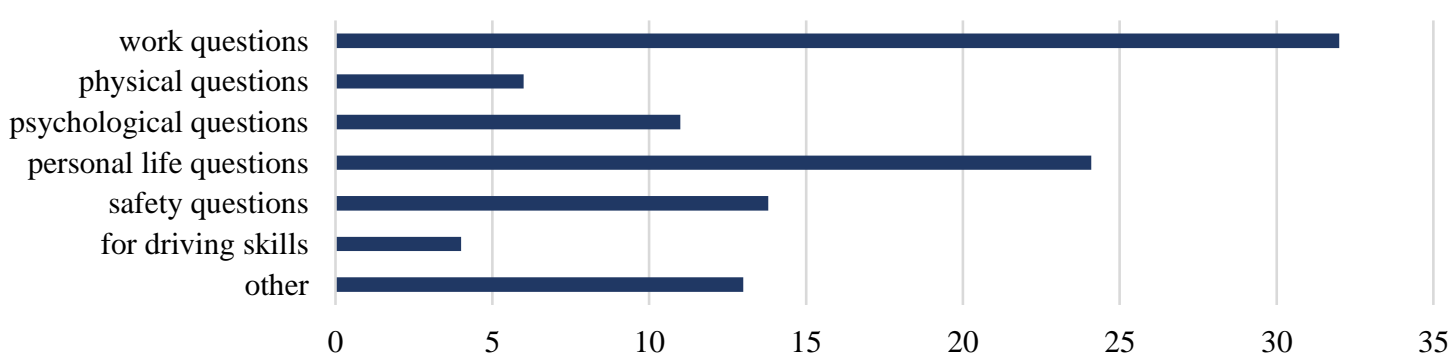

Figure 10. Main coaching fields, Lithuania, \%

\subsection{Contracting terms}

When contracting the coaches identified the following factors as important: termination, responsibilities and confidentiality. When the session is organisational the aspects of confidentiality and responsibilities of the parties become more important, reflecting the challenge sin working in a multi stakeholder environment, where both the sponsor and the individual coachee will hold expectations about the coach and the coaching process (See Figure 11).

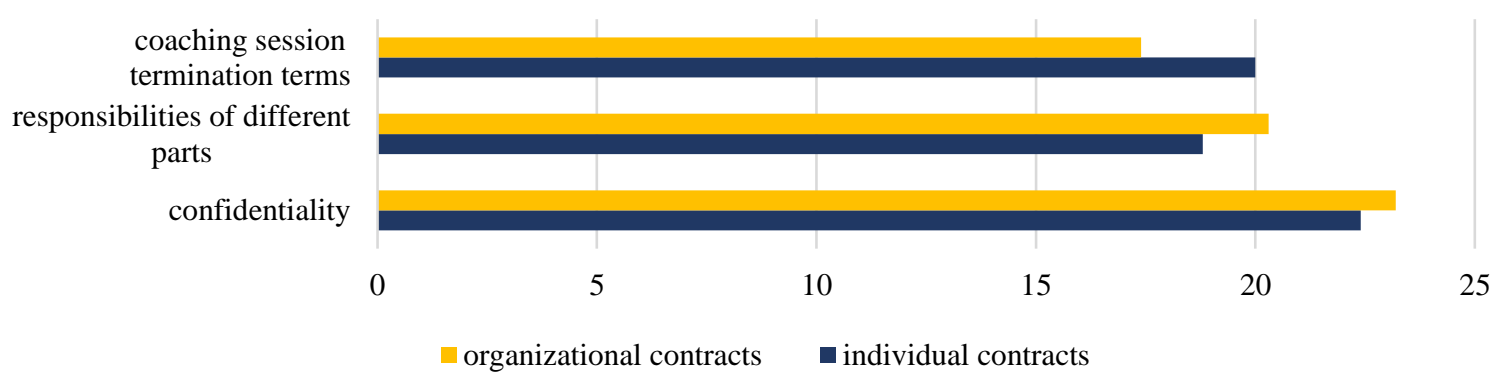

Figure 11. Contract main aspects, Lithuania, \%

\subsection{Coaching background}

If we analyse the data on coach backgrounds', we can see that $24.6 \%$ of Lithuanian coaches are career specialists, $23.1 \%$ are performance and leadership coaches, and $13.8 \%$ works with workplace issues.

\subsection{Methods for Reflection}

We also explored what methods do coaches use to reflect on their practice. The data shows that the most popular method of reflection was self-reflection, with $58 \%$ coaches in Baltic States and more than $75 \%$ coaches in UK using this method. The second most popular method was coaching books with $60 \%$ Baltic State coaches, a little bit more than $62 \%$ EU and $64 \%$ UK coaches reporting their use of this method. We may speculate as to why reflection is lower when education 
attainment was higher, as typically these elements are associated, but these differences may reflect wider cultural or differences in the profile with lower experienced coaches reflecting less than more experienced coaches. More research is need to better understand this difference in practice.

\subsection{Coaching models}

In terms of coaching models there was much in common across Europe, with some models, such as Solution focused and NLP more commonly used in the Baltic States than in Europe or the UK (see Figure No 12).

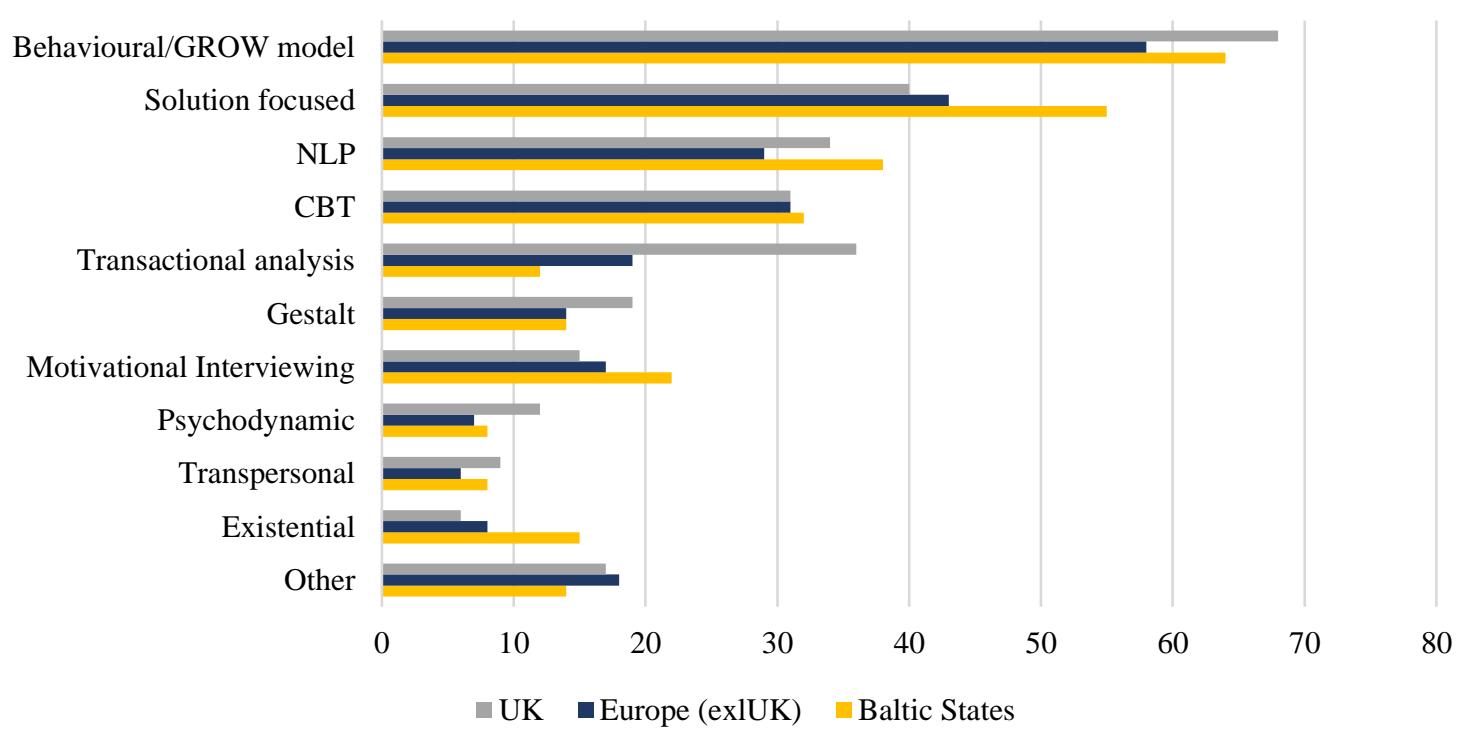

Figure 12. Coaching practise models, $\%$

The data for Lithuania is reported in Figure 13.

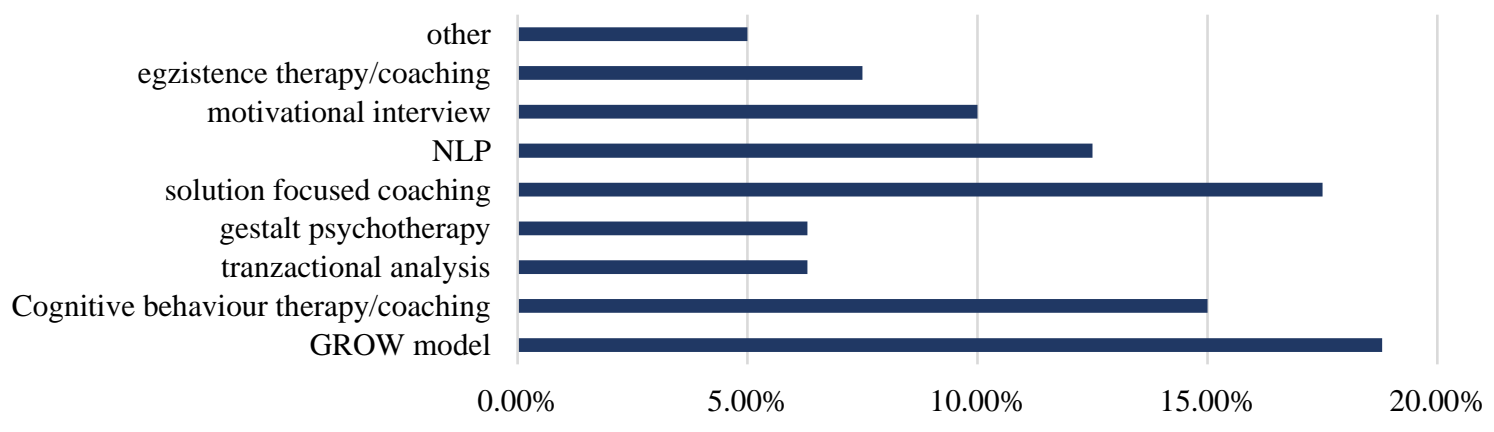

Figure 13. Coaching practice models of Lithuanian coaches, \%

We asked coaches whether they would use different models in different presenting issues and there is some evidence to support this. We had hypothesised, that coaches were most likely to use GROW for career change and presentation 
skills, Cognitive behavioural for workplace stress and motivational interview for a habituated behavioural challenge, like email checking.

The results comparing UK, Europe and the Baltic State coaches is reported in Table 1.

Table 1. What model is used with the following presenting issue, $\%$

\begin{tabular}{|c|c|c|c|}
\hline & BALTIC STATES & EUROPE COUNTRIES & LITHUANIA \\
\hline \multicolumn{4}{|c|}{ Career change } \\
\hline Behavioural/GROW & $48 \%$ & $43 \%$ & $29,8 \%$ \\
\hline Solution focused & $39 \%$ & $28 \%$ & $21,3 \%$ \\
\hline Motivational interviewing & $18 \%$ & $15 \%$ & $14,9 \%$ \\
\hline \multicolumn{4}{|c|}{ Workplace stress } \\
\hline Cognitive behavioural coaching & $34 \%$ & $24 \%$ & $21,3 \%$ \\
\hline NLP & $27 \%$ & $14 \%$ & $14,9 \%$ \\
\hline Behavioural/GROW & $19 \%$ & $17 \%$ & $12,8 \%$ \\
\hline Gestalt therapy & $17 \%$ & $9 \%$ & $14,9 \%$ \\
\hline \multicolumn{4}{|c|}{ Improving presentation skills } \\
\hline Behavioural/GROW & $39 \%$ & $30 \%$ & $22,9 \%$ \\
\hline$N L P$ & $28 \%$ & $16 \%$ & $20 \%$ \\
\hline Solution focused & $26 \%$ & $17 \%$ & $11,4 \%$ \\
\hline $\begin{array}{l}\text { Cognitive behaviour } \\
\text { therapy/coaching }\end{array}$ & $16 \%$ & $17 \%$ & $14,3 \%$ \\
\hline \multicolumn{4}{|c|}{ Persistent checking of non-work emails } \\
\hline Cognitive behavioural coaching & $24 \%$ & $22 \%$ & $24 \%$ \\
\hline Behavioural/GROW & $22 \%$ & $21 \%$ & $16 \%$ \\
\hline$N L P$ & $17 \%$ & $12 \%$ & $20 \%$ \\
\hline
\end{tabular}

\subsection{Continuous professional development (CDP)}

If we would look about coaching self-development, we will see that more than $27 \%$ of Baltic states coaches invests from 16 to 60 hours for personal development and $15 \%$ of coaches invests more than 60 hours (see Figure 14).

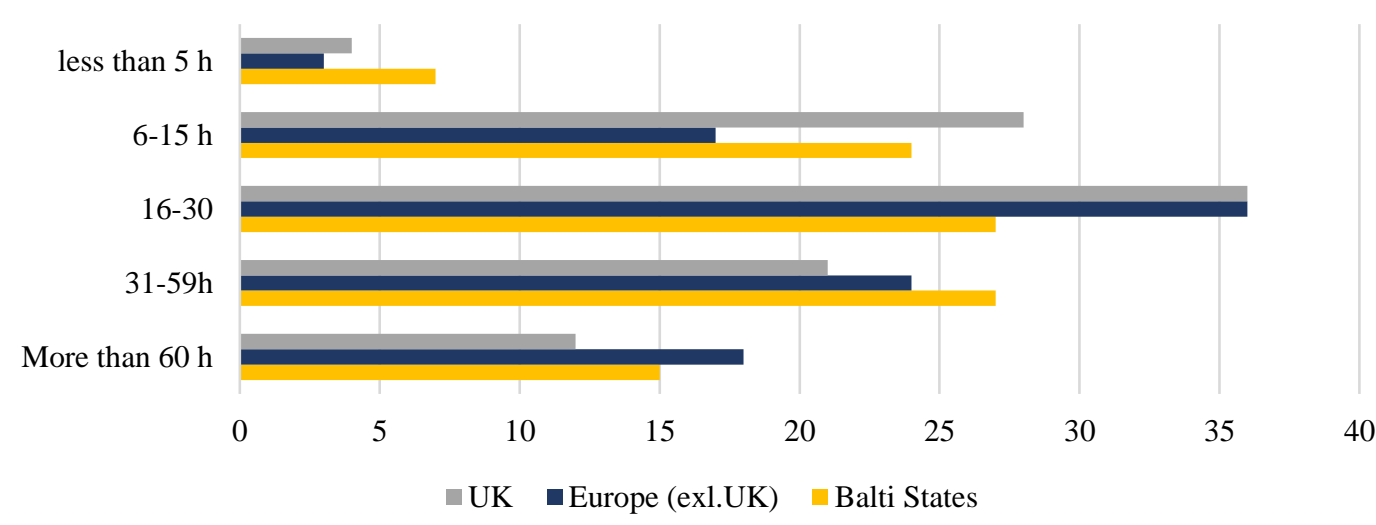

Figure 14. Time invested in continuous professional development, $\%$ 
The data shows that respondents from the Baltic States keeps up to date their knowledge, skills and competences in coaching practise. with more than $64 \%$ of respondents reading coaching books, $62 \%$ attending professional networking events, $55 \%$ attending in short courses in coaching skills and 58\% attending coaching conferences as their means for CPD (see Figure No. 15).

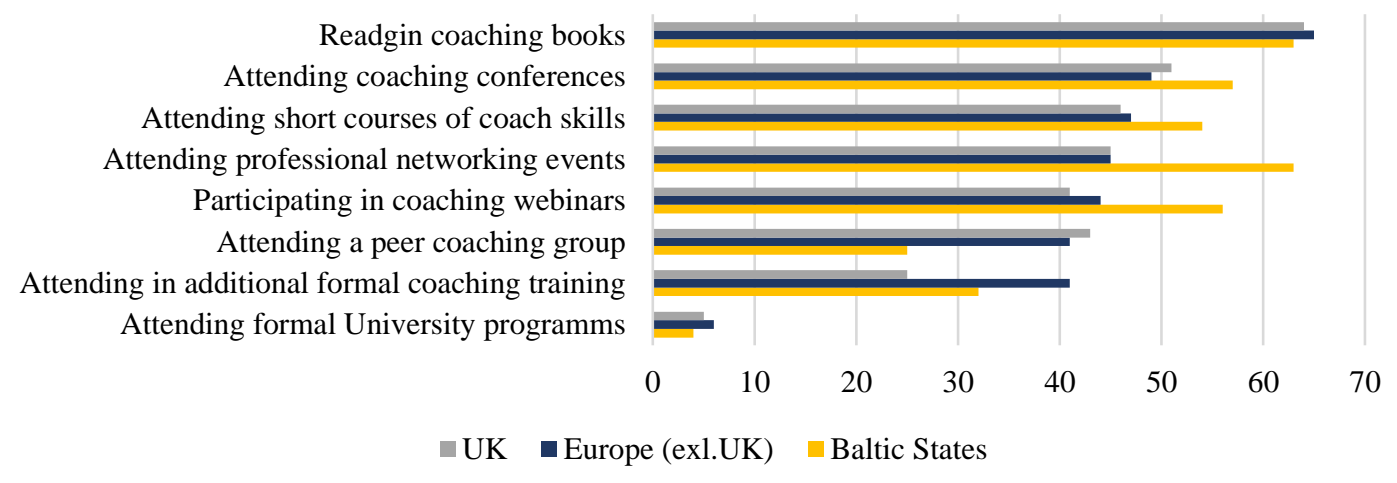

Figure 15. Keeping up to date, $\%$

This data confirms that coaches see professional standards as important and they continue to invest in professional development after qualifying.

\subsection{Supervision}

Supervision has been widely recognised by some countries as an important aspect in coach CPD, and for maintaining ethical practice. In the UK, and some parts of Europe supervision is seen as an essential component for practice and is specified by professional bodies such as the EMCC and Association for Coaching. However other bodies such as the ICF see supervision as desirable rather than essential. Unsurprisingly supervision practice reflects different levels of membership of different professional bodies, with high ICF membership as a percentage of the coaching community related to lower levels of supervision (see Figure No. 16).

We suspect that as the ICF increases its engagement with supervision, that supervision rates will equalise across Europe, including in the Baltic States. This will fuel an increase in demand for supervision training programmes to provide appropriately qualified coach supervisors.

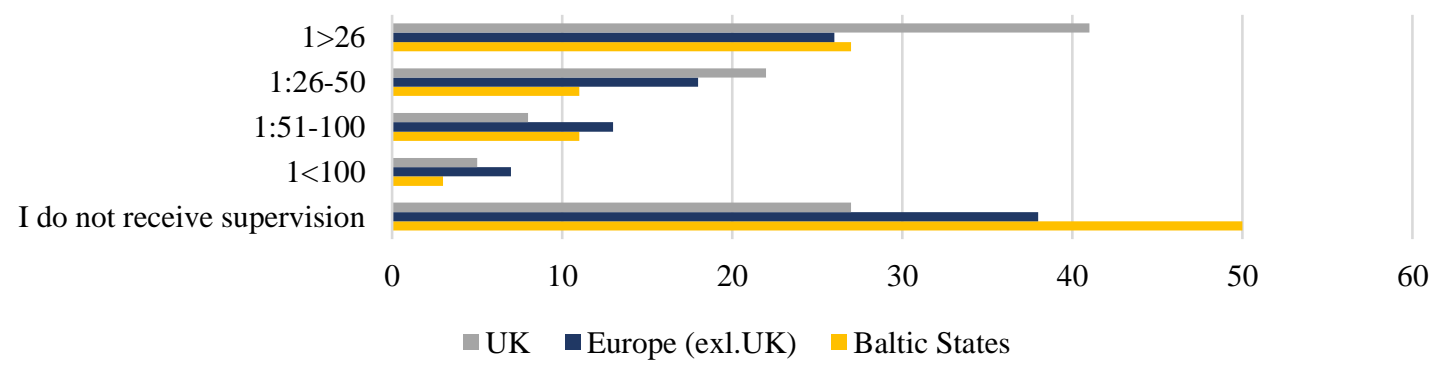

Figure 16. Frequently of supervisions (based on ration of 1 hour of supervision per $\mathrm{X}$ hours of coaching) 
Despite lower levels of supervision, the data shows that coaches in the Baltic States gives a lot of attention to personal professional development.

\subsection{Membership of professional bodies}

Only $35.5 \%$ of coaches who had participated in this research belonged to the International Coach Federation ICF Lithuania chapter. 46,7\% doesn't belong to any other coaching body, and $20 \%$ of participants belongs to other coaching organizations (see Figure No. 17). This was a lower figure than in most other European countries and confirms the status of coaching in the Baltic states as still in development.

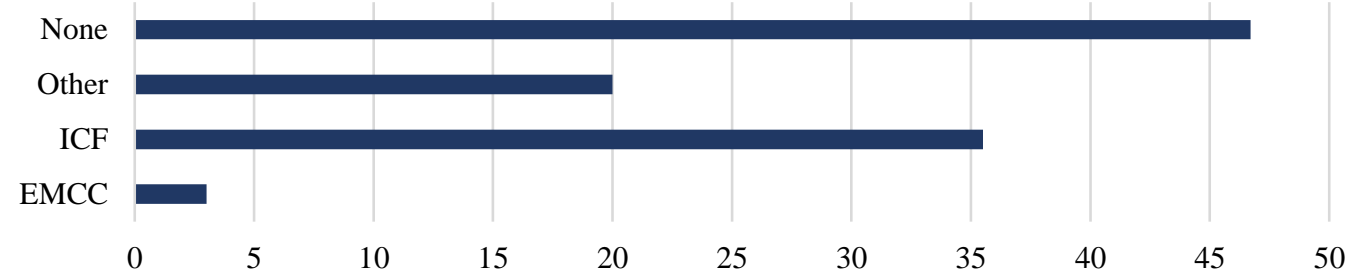

Figure 17. Which coaching and mentoring bodies are you a member of, Lithuania respondents, \%

\section{Conclusions}

This article has focused on areas of distinction for the coaching industry in Lithuania, and the wider Baltic States. It has compared practices with the other European countries that took part in the wider study. The responses suggest that coaching in the Baltic States is broadly comparable with wider European practice and that where differences, such as fee rates, higher levels of female participation, the use of supervision and the lower levels of experience, these reflect economic differences, differences in professional body focus and / or an earlier stage of development of the coaching profession.

Overall coaching is similar reflecting the wider influence of European culture, the impact of global coaching bodies such as the ICF in creating common standards of practice and the impact of international training schools, which delivers training to common global standards. While the existence of global standards and global training could be argued to raise standards, it may also be argued that national cultural differences are squeezed out by Globalisation, or even an 'Americanisation' of coaching, with little room left for national cultural preferences to emerge.

The future of coaching is still emerging and while we argue that standards of training, ethics and continuous professional development, including supervision should be encouraged, we would also argue the case that space needs to be left for national approaches to emerge reflecting regional, national and cultural differences which celebrate global diversity. 


\section{Acknowledgements}

The authors would like to thank colleagues in the European Coaching and Mentoring Research project for their contributions.

\section{References}

Brock, V. (2012). Coaching History and Evolution. Coach Training, Development and Education. V. G. Brock. Master Certified Coach. ACTO. Conference April 20.

Cluterbuck, D., Megginson, D. (2005). Making coaching work: Creating a coaching culture. CIPD Publishing.

Dromantaitè, A. (2014). New approach about Leadership: coaching practice in Lithuanian organizations // Dromantaitè, A., Raišienè, A. G., Vanagas, R. ir kt. Veiksmingos vadybos gairès: teorinès įžvalgos ir Lietuvos organizacijų atvejai“".

Honsova, P., Passmore, J., Brown, H. (2018). What are Czech coaches really doing? A comparison of Czech and European-wide coaching trends // Central European Business Review. 7(3), 42-60. doi: 10.18267/j.cebr.202

Houston, R. E. (1924). Debate coaching in high school // The Quarterly Journal of Speach Education, 10, 127-143.

Jones, R.J., Woods, S.A., Guillaume, Y.R.F. (2015), "The effectiveness of workplace coaching: A meta-analysis of learning and performance outcomes from coaching", Journal of Occupational and Organizational Psychology, 89(2), 249-277. https://doi.org/10.1111/joop.12119

Kovacs, L., Corrie, S. (2017). Building reflective capability to enhance coaching practice // The Coaching Psychologist, 13(1), 4-12.

Passmore, J., Fillery-Travis (2011). A Critical Review of executive coaching research: A decade of progress and what's to come //Coaching: An International Journal of Theory, Practice and Research, 4(2), 70-88.

Passmore, J., Lai, Y-L. (2019) Coaching Psychology: Exploring definitions and research contribution to practice // International Coaching Psychology Review, 14(2) 69-83.

Passmore, J., Brown, H., Csigas, Z. (2017). The European Coaching and Mentoring Research Consortium // The State of Play in European Coaching \& Mentoring - Executive Report. Henley-on-Thames: Henley Business School and EMCC International.

Passmore, J., Brown, H., Peebles, D., Grajfoner, D. (2018). The European Coaching and Mentoring Research Consortium // The State of Play in Scottish Coaching. Henley-on-Thames: Henley Business School.

Passmore, J., Brown, H., Tee, D. (2018). Distinctions in Practice within Coaching in Scotland // The Coaching Psychologist. 14(2), 80-88.

Tee, D., Passmore, J., Brown, H. (2019). Distinctions in coaching practice between England and the Rest of Europe // The Coaching Psychologist. 15(2), 30-38.

Schor, J., Bachkirova, T., Smith, L. (2015). From competencies to capabilities in the assessment and accreditation of coaches // International Journal of Evidence Based Coaching \& Mentoring, 13(2), 123-140.

Theeboom, T., Beersma, B., Van Vianen, A.E.M. (2014), "Does coaching work? A metaanalysis on the effects of coaching on individual level outcomes in an organizational context", // The Journal of Positive Psychology, 9(1), 1-18.

Trueblood, T. C. (1911). Coaching a debating team. Public Speaking Review N1, p. 84-85.

Whitmore, J. (2002) Coaching for Performance. 3rd Edition. London; Nicholas Brealey. 